Note

\title{
Validation Study of a Commercial Aflatoxin Detection Kit according to the Notification Method in Japan
}

\author{
HIROSHI MORITA ${ }^{1 *}$, ANJA TISCHER ${ }^{2}$, BERNHARD RECK ${ }^{2}$, \\ MONIKA MARUHN ${ }^{2}$ AND WALTER LÜBBE ${ }^{2}$ \\ ${ }_{1}^{1}$ AZmax Co. Ltd. 1-10 Hatchobori 2, Chuo-ku, Tokyo 104-0032, Japan \\ ${ }^{2}$ R-Biopharm AG. An der neuen Bergstrasse 17, 64297 Darmstadt, Germany
}

Received 10 January, 2013/Accepted 7 August, 2013

\begin{abstract}
A commercial aflatoxin detection ELISA kit, “RIDASCREEN ${ }^{\circledR}$ FAST Aflatoxin”, was validated with corn samples naturally contaminated with aflatoxin and non-contaminated reference corn samples according to the Japanese Notification Method ShokuAnHatsu 0816-7. The trueness, intra-laboratory repeatability, intermediate precision, limit of detection and limit of quantitation were found to be $91 \%, 10 \%, 6.4 \%, 0.6 \mu \mathrm{g} / \mathrm{kg}$ and $2 \mu \mathrm{g} / \mathrm{kg}$, respectively, and the performance of the kit was recognized as complying with all criteria in the Supplement Table of the Notification. These data suggest that this kit is useful as a simplified device to screen out negative corn samples contaminated with less than $4 \mu \mathrm{g} / \mathrm{kg}$.
\end{abstract}

Key words : Total aflatoxins / ELISA kit / Validation / Notification method / Screening.

In Japan, the importation of food from various foreign countries is increasing year by year. The registration for the importation approval totalized more than 2 million $(2,001,020)$ in 2010 and their weight was $31,801,900 t$ (MHLW, 2011a). Aflatoxins, abbreviated as AFs hereafter, are one of the important contaminants to check for in imported foods. Effective tools to analyze AFs in a large range of samples are required by many laboratories.

Originally, Japanese regulations stated that all food products should contain no AFs, but in fact, only AFB was regulated at a level of $10 \mu \mathrm{g} / \mathrm{kg}$ (MHW, 1971). Recently, according to the increasing volume of international trade, regulations had to be adjusted to reflect global trends. Therefore, the regulation was amended to deal with the total AFs from $\mathrm{AFB}_{1}$ (MHLW, 2011b). Then, the official method to analyze total AFs was notified (MHLW, 2011c).

The commercially available AF detection kit, "RIDASCREEN ${ }^{\circledR}$ FAST Aflatoxin" (R-Biopharm, Darmstadt, Germany), abbreviated as "this kit" hereafter, is a competitive ELISA kit for the quantitative analysis of AF in cereals and feed. In Japan, this kit was

*Corresponding author. Tel: +81-3-5543-1630, Fax: +81-35543-0312, morita (a)azmax.co.jp validated by S.-Konishi et al. together with other test kits (S.-Konishi et al. 2007), and enlisted as one of simplified devices (or test kits) in screening out AFB $_{1}$ negative corn samples for further HPLC or LC-MS/MS analysis in the Supplement sheet 2 of the notification (MHLW, 2006). Together with the notification on the method for the detection of total AFs, screening out AF negative corn samples with a simplified device was permitted in another notification as long as the device was validated and complied with all requirements in the Supplement Table in the notification (MHLW, 2011d). In this notification, the samples found to contain total AFs at less than $4 \mu \mathrm{g} / \mathrm{kg}$ can be interpreted as negative with the simplified device and would not have to be subject to further analysis. However, the samples found to contain AFs at $4 \mu \mathrm{g} / \mathrm{kg}$ or more cannot be interpreted as negative with the simplified device only and should be analyzed further with HPLC or LC-MS/ MS. Therefore, it was necessary to conduct validation studies of this kit as to whether it complies with all requirements in the Supplement Table. Especially, it was also important to check whether this kit precisely detects around $4 \mu \mathrm{g} / \mathrm{kg}$ of AFs.

Naturally AF-contaminated or non-contaminated reference standard corn materials (Trilogy Analytical Laboratory, Inc., Washington, MO, USA) were used in 
this study. The concentration of total AFs in the naturally contaminated materials was confirmed by a method of AOAC OMA994.08 by the company (Trucksess et al., 1994). The sample preparation was carried out as follows. Five (5) $\mathrm{g}$ of the well ground corn sample was mixed with $25 \mathrm{ml}$ of methanol (70\%). The mixture was shaken vigorously for $3 \mathrm{~min}$. The resultant homogenate was filtered through a Whatman No.1 filter paper. One (1) $\mathrm{ml}$ of the filtrate was diluted with $1 \mathrm{ml}$ of distilled water. Fifty (50) $\mu \mathrm{I}$ of the diluted filtrate was used for the ELISA determination. The ELISA procedure was carried out according to the manual of this kit. The tests were done in duplicate by using 2 wells. Trilogy's standard AF reagents were used as a reference in this study.

In order to investigate the recovery of each $A F B_{1}, B_{2}$, $G_{1}$ or $G_{2}$ with this kit, each of the 4 AF species were separately spiked into the non-contaminated reference corn sample at a concentration of $5 \mu \mathrm{g} / \mathrm{kg}$. Each sample was analyzed with this kit as $4.3,3.8,3.0$ and $1.9 \mu \mathrm{g} / \mathrm{kg}$, respectively. The recovery of each AF species was calculated as $86,76,60$ and $38 \%$, respectively. Single contamination by $A F G_{2}$ has not been reported by the survey of the Food Safety Commission of Japan. In all cases of $\mathrm{G}_{2}$ contamination, $G_{2}$ appeared together with $B_{1}, B_{2}$ and $G_{1}$ (FSC 2009). As contamination by only $G_{2}$ is almost completely unlikely in the present situation, the low recovery, 38\%, of $G_{2}$ has no significant influence on the screening of total AFs practically. The recovery of $G_{1}$ was also low at $60 \%$. However, in all cases of $G_{1}$ contamination, $G_{1}$ always appeared together with $B_{1}$, or $B_{1}, B_{2}$ and $G_{2}$ (FSC 2009). Even if a positive sample ( $>10 \mu \mathrm{g} / \mathrm{kg})$ were to include only $G_{1}$, the sample would not give a false negative result $(<4 \mu \mathrm{g} / \mathrm{kg})$. The low recovery of $G_{1}$ or $G_{2}$ would not affect the screening of total AFs practically.

Each of the 4 AF species, $B_{1}, B_{2}, G_{1}$ and $G_{2}$, were separately spiked into the non-contaminated reference corn samples to a final concentration of $5,15,45,135$ $\mu \mathrm{g} / \mathrm{kg}$. AFs were extracted and determined with this kit. $B / B_{0}$ values in each concentration were calculated with a percentage rate of the optical absorbance at each concentration to that of the $0 \mu \mathrm{g} / \mathrm{kg}$ standard solution in this kit. $\mathrm{IC}_{50}$ (50\% inhibitory concentration: the concentration when $\mathrm{B} / \mathrm{B}_{0}$ value shows $50 \%$ ) was also calculated. The cross reactivity was calculated according to the guidelines of the ISO 18330:2003 (IDF 188:2003) (ISO 18330), as the percentage ratio of the $I C_{50}$ value of the AFB1 to that for competitors. The $I C_{50}$ values for $A F B_{1}, B_{2}, G_{1}$ and $G_{2}$ were $10.3,11.8,14.2$ and $28.9 \mu \mathrm{g} / \mathrm{kg}$, respectively. The results obtained using this kit showed the following cross reactivity for each AF: $87 \%, 73 \%$ and $36 \%$ for $B_{2}, G_{1}$ and $G_{2}$,
TABLE 1. Determination of cross reactivities of $A F B_{2}, G_{1}$ and $\mathrm{G}_{2}$ to $A \mathrm{FB}_{1}$.

Each AF species was separately spiked into the non-contaminated corn samples to concentrations of 5, 15, 45, $135 \mu \mathrm{g} /$ $\mathrm{kg}$. AFs were extracted from each sample and each value of $\mathrm{B} / \mathrm{B}_{0}$ and $\mathrm{IC}_{50}$ was calculated. The percentage of $\mathrm{IC}_{50}$ of $\mathrm{AFB}$ to each $\mathrm{AF}$ species was calculated as the cross reactivity.

\begin{tabular}{|c|c|c|c|c|c|}
\hline \multirow{3}{*}{$\begin{array}{c}\text { AF } \\
\text { concentra- } \\
\text { tion }(\mu \mathrm{g} / \mathrm{kg})\end{array}$} & \multicolumn{5}{|c|}{$\mathrm{B} / \mathrm{B}_{0}(\%)$} \\
\hline & Standards in & \multicolumn{4}{|c|}{ Corn materials spiked } \\
\hline & $\mathrm{B}_{1}$ & $\mathrm{~B}_{1}$ & $\mathrm{~B}_{2}$ & $\mathrm{G}_{1}$ & $\mathrm{G}_{2}$ \\
\hline 1.7 & 83 & - & - & - & - \\
\hline 5 & 64 & 67 & 69 & 74 & 81 \\
\hline 15 & 37 & 42 & 44 & 47 & 65 \\
\hline 45 & 18 & 20 & 22 & 25 & 42 \\
\hline 135 & - & $8.8^{*}$ & $11^{*}$ & $12^{*}$ & 21 \\
\hline $\begin{array}{c}\mathrm{IC}_{50} \\
(\mu \mathrm{g} / \mathrm{kg})\end{array}$ & 8.9 & 10 & 12 & 14 & 29 \\
\hline $\begin{array}{c}\text { Cross reac- } \\
\text { tivity (\%) }\end{array}$ & - & 100 & 87 & 73 & 36 \\
\hline
\end{tabular}

*: Values, out of quantitation range.

TABLE 2. Intra-laboratory repeatability AFs were extracted 10 times from each naturally contaminated sample and each concentration was determined with this kit. The average concentration and the RSD were determined for each sample. The average value of RSD was calculated as the intra-laboratory repeatability.

\begin{tabular}{ccccc}
\hline \multirow{2}{*}{ Extraction } & \multicolumn{5}{c}{$\begin{array}{c}\text { Naturally contaminated reference } \\
\text { standard materials }(\mu \mathrm{g} / \mathrm{kg})\end{array}$} \\
\cline { 2 - 5 } & 2.7 & 4.5 & 9.4 & 19 \\
\hline 1 & 3.4 & 3.7 & 9.4 & 21 \\
2 & 3.3 & 4.6 & 10.4 & 22 \\
3 & 3.1 & 3.6 & 11.0 & 19 \\
4 & 2.9 & 3.7 & 9.4 & 18 \\
5 & 2.8 & 4.3 & 9.3 & 18 \\
6 & 3.3 & 4.2 & 9.2 & 20 \\
7 & 2.9 & 4.6 & 9.1 & 16 \\
8 & 2.9 & 4.5 & 8.9 & 16 \\
9 & 3.2 & 4.1 & 10.7 & 20 \\
10 & 3.2 & 5.1 & 11.3 & 25 \\
\hline Average concentration $(\mu \mathrm{g} / \mathrm{kg})$ & 3.1 & 4.2 & 9.9 & 20 \\
\hline Standard deviation $(\mu \mathrm{g} / \mathrm{kg})$ & 0.21 & 0.48 & 0.88 & 2.8 \\
\hline RSD $(\%)$ & 6.8 & 11 & 8.9 & 14 \\
\hline Intra-laboratory repeatability $(\%)$ & \multicolumn{5}{c}{10} \\
\hline
\end{tabular}

respectively, as shown in Table 1 . There was no cross reactivity to deoxynivalenol, fumonisin $B_{1}$, zearalenone, ochratoxin A or T-2 toxin.

Corn reference samples naturally contaminated with $2.7,4.5,9.4$ or $19 \mu \mathrm{g} / \mathrm{kg}$ of total AF were each subjected to extraction 10 times in a day according to the manual and examined with this kit in order to obtain the average concentration and the relative standard deviation (abbreviated as RSD here). The intralaboratory repeatability was calculated as the average 
TABLE 3. Trueness and intermediate precision

AFs were extracted twice from each naturally contaminated sample and each concentration was repeatedly determined with this kit for 5 days. The average concentration, recovery and the RSD were determined for each sample. The average value of recovery was calculated as the trueness. The average value of each RSD was calculated as the intermediate precision

\begin{tabular}{|c|c|c|c|c|c|}
\hline \multirow[t]{2}{*}{ Day } & \multirow[t]{2}{*}{ Extraction } & \multicolumn{4}{|c|}{$\begin{array}{c}\text { Naturally contaminated reference } \\
\text { standard materials }(\mu \mathrm{g} / \mathrm{kg})\end{array}$} \\
\hline & & 2.7 & 4.5 & 9.4 & 19 \\
\hline \multirow[t]{2}{*}{1} & 1st & 2.3 & 4.7 & 9.4 & 16 \\
\hline & 2nd & 2.8 & 4.2 & 8.1 & 14 \\
\hline \multirow[t]{2}{*}{2} & $1 s t$ & 2.6 & 4.0 & 7.8 & 16 \\
\hline & 2nd & 2.4 & 3.9 & 7.3 & 16 \\
\hline \multirow[t]{2}{*}{3} & $1 \mathrm{st}$ & 2.6 & 4.4 & 8.7 & 16 \\
\hline & 2nd & 2.5 & 4.2 & 7.5 & 16 \\
\hline \multirow[t]{2}{*}{4} & $1 s t$ & 2.6 & 4.5 & 8.1 & 16 \\
\hline & 2nd & 2.6 & 4.4 & 8.1 & 14 \\
\hline \multirow[t]{2}{*}{5} & $1 s t$ & 2.7 & 4.3 & 8.1 & 18 \\
\hline & 2nd & 2.5 & 4.5 & 7.6 & 16 \\
\hline \multicolumn{2}{|c|}{ Average $(\mu \mathrm{g} / \mathrm{kg})$} & 2.6 & 4.3 & 8.1 & 16 \\
\hline \multicolumn{2}{|c|}{ Recovery (\%) } & 96 & 96 & 86 & 84 \\
\hline \multicolumn{2}{|c|}{$\mathrm{RSD}(\%)$} & 5.6 & 5.2 & 7.6 & 7.2 \\
\hline \multicolumn{2}{|c|}{ Average recovery (\%) } & \multicolumn{4}{|c|}{91} \\
\hline \multicolumn{2}{|c|}{ Intermediate precision (\%) } & \multicolumn{4}{|c|}{6.4} \\
\hline
\end{tabular}

of the RSD in each concentration. As shown in Table 2, the RSD or the intra-laboratory repeatability was between $6.8 \%, 14 \%$ and $10 \%$, respectively. The results show a good compliance to the requirement for the intra-laboratory repeatability of " $<25 \%$ " not only in the low concentration range which is required in the AF screening but also in whole range detectable with this kit.

Corn reference samples naturally contaminated with $2.7,4.5,9.4$ or $19 \mu \mathrm{g} / \mathrm{kg}$ of total AF were each subjected to extraction twice in a day according to the manual and examined with this kit. This was repeated continuously for 5 days. The average concentration, recovery and RSD of each sample were calculated with each value detected by this kit. The trueness was defined here as the percentage recovery of the concentration. The intermediate precision was calculated with each RSD. As shown in Table 3, the trueness or the intermediate precision was calculated as $91 \%$ and $6.4 \%$, respectively, so this kit conforms with the requirement for the trueness or the intermediate precision as "70\%-120\%" and "<35\%", respectively, in the Supplement Table. Since high trueness, 96\% and low RSD, $5.2 \%$, were recognized in $4.5 \mu \mathrm{g} / \mathrm{kg}$ contaminated samples, it suggests that this kit is practically useful as a tool with which we can accurately screen out negative samples at the $4 \mu \mathrm{g} / \mathrm{kg}$ level.

Though the inter-laboratory reproducibility study is
TABLE 4. Inter-laboratory reproducibility AFs were extracted twice from the naturally $4.5 \mu \mathrm{g} / \mathrm{kg}$ contaminated sample and each concentration was repeatedly determined with this kit for 5 days in 3 laboratories. The average concentration was determined in each laboratory. The inter-laboratory reproducibility was calculated as the RSD in the Supplement sheet 2 between 3 laboratories to the average concentration of 3 laboratories.

\begin{tabular}{|c|c|c|c|c|}
\hline \multirow[t]{2}{*}{ Day } & \multirow[t]{2}{*}{ Extraction } & \multicolumn{3}{|c|}{$\begin{array}{l}\text { Naturally contaminated reference } \\
\text { standard materials }(\mu \mathrm{g} / \mathrm{kg})\end{array}$} \\
\hline & & Lab.A & Lab.B & Lab.C \\
\hline \multirow[t]{2}{*}{1} & $1 s t$ & 4.7 & 4.3 & 4.9 \\
\hline & 2nd & 4.2 & 4.5 & 5.4 \\
\hline \multirow[t]{2}{*}{2} & $1 s t$ & 4.0 & 3.8 & 4.1 \\
\hline & 2nd & 3.9 & 3.4 & 4.4 \\
\hline \multirow[t]{2}{*}{3} & $1 s t$ & 4.4 & 5.2 & 4.5 \\
\hline & 2nd & 4.2 & 5.2 & 4.6 \\
\hline \multirow[t]{2}{*}{4} & $1 \mathrm{st}$ & 4.5 & 4.3 & 5.4 \\
\hline & 2nd & 4.4 & 4.5 & 5.3 \\
\hline \multirow[t]{2}{*}{5} & 1st & 4.3 & 3.8 & 4.6 \\
\hline & 2nd & 4.5 & 4.7 & 4.2 \\
\hline \multicolumn{2}{|c|}{ Average $(\mu \mathrm{g} / \mathrm{kg})$} & 4.3 & 4.4 & 4.7 \\
\hline \multicolumn{2}{|c|}{ Recovery (\%) } & 96 & 97 & 105 \\
\hline \multicolumn{2}{|c|}{ Intermediate precision (\%) } & 5.4 & 14 & 10 \\
\hline \multicolumn{2}{|c|}{ Average of 3 labs $(\mu \mathrm{g} / \mathrm{kg})$} & & 4.5 & \\
\hline \multicolumn{2}{|c|}{ Average recovery (\%) } & & 99 & \\
\hline \multicolumn{2}{|c|}{ Standard deviation $(\mu \mathrm{g} / \mathrm{kg})$} & & 0.23 & \\
\hline \multicolumn{2}{|c|}{$\begin{array}{c}\text { Inter-laboratory } \\
\text { reproducibility (\%) }\end{array}$} & & 5.2 & \\
\hline
\end{tabular}

not required in the Supplement Table, it was conducted in this study. A corn reference sample naturally contaminated with $4.5 \mu \mathrm{g} / \mathrm{kg}$ of total AFs was subjected to extraction twice in a day according to the manual and examined with this kit in 3 different laboratories. This was repeated continuously for 5 days. The average concentration, recovery and RSD of each laboratory were calculated with each value detected by this kit. Both the average recovery and the standard deviation of results from 3 laboratories were calculated from the recovery and the average concentration of each laboratory. The inter-laboratory reproducibility was calculated as the rate of standard deviation to the average of 3 concentrations. As shown in Table 4, the average recovery and the inter-laboratory reproducibility were recognized as $99 \%$ and $5.2 \%$, respectively. As a high recovery percentage and low value indicating good inter-laboratory reproducibility were recognized, this kit may practically be useful as a device with which we can screen out negative samples at the $4 \mu \mathrm{g} / \mathrm{kg}$ level.

The recovery and the intermediate precision were calculated in each laboratory. The recovery from laboratory A, B and C was found to be $96 \%, 97 \%$ and $105 \%$, respectively. The intermediate precision was $5.4 \%, 14 \%$ and $10 \%$, respectively. All of the values 
TABLE 5. Limit of detection and limit of quantitation AFs were extracted from non-contaminated sample ten times and determined with this kit. The concentrations were obtained from the calibration curve with extrapolation. The limit of detection was calculated with the average concentration with the addition of the 2 -fold value of the S.D. The limit of quantitation was calculated with the average concentration with the addition of the 9-fold value of the S.D.

\begin{tabular}{ccc}
\hline Sample & $\mathrm{B} / \mathrm{B}_{0}(\%)$ & $\mu \mathrm{g} / \mathrm{kg}$ \\
\hline 1 & 99 & 0.2 \\
2 & 97 & 0.4 \\
3 & 98 & 0.2 \\
4 & 97 & 0.3 \\
5 & 102 & 0.0 \\
6 & 96 & 0.4 \\
7 & 98 & 0.3 \\
8 & 101 & 0.0 \\
9 & 104 & 0.0 \\
10 & 103 & 0.0 \\
\hline Average & 100 & 0.2 \\
\hline S.D. & - & 0.2 \\
\hline LOD & - & 0.6 \\
\hline LOQ & - & 2 \\
\hline
\end{tabular}

LOD: limit of determination, LOQ: limit of quantitation

TABLE 6. Stability in storage

This kit was stored at $4-8^{\circ} \mathrm{C}$ for several months and each $\mathrm{AF}$ standard solution was analyzed every 3 months. Changes in $B / B_{0}$ values and $I C_{50}$ values were checked. $n=5$.

\begin{tabular}{|c|c|c|c|c|c|c|c|}
\hline \multirow[b]{3}{*}{ Stds. } & \multirow{3}{*}{$\begin{array}{l}\text { Reference conc. } \\
\qquad(\mu \mathrm{g} / \mathrm{kg})\end{array}$} & \multicolumn{6}{|c|}{ Storage period (months) } \\
\hline & & \multicolumn{2}{|c|}{0} & \multicolumn{2}{|c|}{3} & \multicolumn{2}{|c|}{6} \\
\hline & & $\mathrm{B} / \mathrm{B}_{0}$ & RSD & $\mathrm{B} / \mathrm{B}_{0}$ & RSD & $\mathrm{B} / \mathrm{B}_{0}$ & RSD \\
\hline 1 & 0 & 100 & 1.1 & 100 & 1.3 & 100 & 3.6 \\
\hline 2 & 1.7 & 85 & 1.4 & 86 & 1.9 & 86 & 2.3 \\
\hline 3 & 5 & 66 & 2.2 & 66 & 2.5 & 71 & 2.2 \\
\hline 4 & 15 & 41 & 1.6 & 41 & 2.4 & 44 & 5.4 \\
\hline 5 & 45 & 18 & 5.2 & 18 & 1.3 & 22 & 2.4 \\
\hline \multicolumn{2}{|c|}{$\mathrm{IC}_{50}(\mu \mathrm{g} / \mathrm{kg})$} & \multicolumn{2}{|c|}{10} & \multicolumn{2}{|c|}{10} & \multicolumn{2}{|c|}{10} \\
\hline \multicolumn{2}{|c|}{ RSD (\%) } & \multicolumn{6}{|c|}{9.8} \\
\hline
\end{tabular}

Stds: Standard solutions.

Values of $\mathrm{B} / \mathrm{B}_{0}$ and $\mathrm{RSD}$ were expressed with percentages.

conformed to the requirements in the Supplement.

Ten (10) non-contaminated reference corn samples were subjected to extraction and the total AF concentration was analyzed with this kit. The concentrations were estimated with extrapolation of the calibration curve. The limit of detection was calculated with the average of 10 concentrations plus double of the standard deviation. As there was no description about how to calculate the limit of quantitation in the requirements of the Supplement, it was calculated with the average of 10 concentrations plus 9 times the value of the standard deviation according to the DIN 32645 (DIN, 2008). As shown in the Table 5, the limit of
TABLE 7. Batch to batch variation A $4.5 \mu \mathrm{g} / \mathrm{kg}$ AF naturally contaminated sample was subject to extraction twice and analyzed with 3 different lots of this kit. The recovery and the RSD were calculated.

\begin{tabular}{cccc}
\hline Lot & Extraction & Concn. $(\mu \mathrm{g} / \mathrm{kg})$ & Recovery $(\%)$ \\
\hline$\# 1$ & 1st & 4.7 & 104 \\
& 2nd & 4.2 & 93 \\
\hline$\# 2$ & 1 st & 4.0 & 89 \\
& $2 \mathrm{nd}$ & 4.0 & 89 \\
\hline$\# 3$ & $1 \mathrm{st}$ & 5.2 & 116 \\
& $2 \mathrm{nd}$ & 4.2 & 92 \\
\hline \multicolumn{2}{c}{ Average } & 4.4 & 97 \\
\hline \multicolumn{2}{c}{ RSD (\%) } & 11 & -
\end{tabular}

TABLE 8. Ruggedness of the incubation temperature. A $4.5 \mu \mathrm{g} / \mathrm{kg}$ AF naturally contaminated sample was subject to extraction twice and analyzed with incubation at 3 different temperatures. The recovery and the RSD were calculated.

\begin{tabular}{cccc}
\hline $\begin{array}{c}\text { Incubation } \\
\text { temp. }\left({ }^{\circ} \mathrm{C}\right)\end{array}$ & Extraction & $\begin{array}{c}\text { Concentration } \\
(\mu \mathrm{g} / \mathrm{kg})\end{array}$ & Recovery $(\%)$ \\
\hline \multirow{2}{*}{28} & $1 \mathrm{st}$ & 4.8 & 107 \\
& $2 \mathrm{nd}$ & 4.0 & 89 \\
\hline 23 & $1 \mathrm{st}$ & 4.7 & 104 \\
& $2 \mathrm{nd}$ & 4.2 & 93 \\
\hline 30 & $1 \mathrm{st}$ & 4.5 & 100 \\
& $2 \mathrm{nd}$ & 4.0 & 89 \\
\hline \multicolumn{2}{c}{ Average } & 4.4 & 97 \\
\hline \multicolumn{2}{c}{ RSD (\%) } & 7.9 & - \\
\hline
\end{tabular}

detection and the limit of quantitation were found to be $0.6 \mu \mathrm{g} / \mathrm{kg}$ and $2 \mu \mathrm{g} / \mathrm{kg}$, respectively. The quantitation limit of $2 \mu \mathrm{g} / \mathrm{kg}$ was the same value as the requirement $(2 \mu \mathrm{g} / \mathrm{kg})$ in the Supplement Table.

We checked the stability within expiration, batch to batch variation and the ruggedness also according to the Supplement Table. There is no description of the acceptable range in the Supplement Table. As shown in Table 6 , the fluctuation of the $\mathrm{IC}_{50}$ was seemed to be at an acceptable level for 6 months (RSD: 9.8\%). Table 7 shows there was no big difference between 3 lots (RSD: 11\%). Table 8 shows there was no big fluctuation on the activity with incubation temperature at the range between $18^{\circ} \mathrm{C}$ and $30^{\circ} \mathrm{C}$ (RSD:7.9\%).

From these data, this test kit meets with all requirements listed in the Supplement Table of the notification (MHLW, 2011d). This kit may be useful as a convenient device for screening out corn samples contaminated with less than $4 \mu \mathrm{g} / \mathrm{kg}$ total AFs. This kit is useful not only for Japanese analysts but also for people who want to export corn to Japan.

\section{ACKNOWLEDGEMENT}

We wish to express our deep thanks to Dr. Bruce Malone, Trilogy Analytical Laboratories, for his 
cooperation in the inter-laboratory validation study. We thank Simon Bevis, R-Biopharm Rhône, for his careful reading of the manuscript.

\section{REFERENCES}

DIN 32645:2008-11. Chemische Analytik- NachweisErfassungs-und Bestimmungsgrenze unter Wiederholbedingungen-Begriffe, Verfahren, Auswertung. pp12, Bestimmungsgrenze. (in German).

Food Safety Commission (2009) FuShoku\#261. The evaluation report on national survey of mycotoxins, total aflatoxins. (in Japanese).

ISO 18330:2003 (IDF 188:2003) Milk and milk products. - Guidelines for the standardized description of immunoassay or receptor assays for the detection of antimicrobial residues.

Ministry of Health and Welfare (1971) The notification KanShoku \#128. (in Japanese).

Ministry of Health, Labour and Welfare (2006) The notification ShokuAnKanHatsu \#0713001. The method of examination on aflatoxins in corn. (in Japanese).

Ministry of Health, Labour and Welfare (2011a) The statistics on monitoring of the imported foods in 2010. (in
Japanese)

Ministry of Health, Labour and Welfare (2011b) The notification ShokuAnHatsu \#0331-1. Treatment of foods contaminated with aflatoxins. (in Japanese).

Ministry of Health, Labour and Welfare (2011c) The notification ShokuAnHatsu \#0816-1, Method of examination on total aflatoxins. (in Japanese).

Ministry of Health, Labour and Welfare (2011d) The notification ShokuAnHatsu \#0816-7, Method of examination on total aflatoxins in corn. (in Japanese)

Ministry of Health, Labour and Welfare (2012) The notification ShokuAnYuHatsu \#0330-3, Implementation of examination orders based on the food sanitation law article 26, section 3. (in Japanese).

S-Konishi, Y., Tanaka, T., Sugita, Y., Inoue, Y., and Nakajima, M. (2007) An inter- laboratory study to validate quantitative and qualitative immunoassay kits for screening test of aflatoxin $\mathrm{B}_{1}$ in corn. Mycotoxins, $\mathbf{5 7}, 75-80$.

Trucksess, M., Stack, M.E., Nesheim, S., Albert, R.H., and Romer, T. (1994) Multifunctional column coupled with liquid chromatography for detection of aflatoxin $B_{1}, B_{2}, G_{1}$ and $\mathrm{G}_{2}$ in corn, almonds, brazil nuts, peanuts, and pistachio nuts. J. AOAC International. 77, 1512-1521. AOAC Official Method 994.08. 